\title{
Standards for University Libraries
}

\section{Foreword}

The following statement of university library standards has been prepared by a joint committee established by the Association of Research Libraries and the Association of College and Research Libraries. A draft of the statement appeared in the April 1978 issue of College \& Research Libraries News.

In August 1978, the Joint ARL-ACRL Committee on University Library Standards revised this draft. On October 26, 1978, the ARL membership unanimously endorsed the statement as revised. At the ALA Midwinter Meeting in January 1979, the ACRL Board also voted to ratify the revised statement. "Standards for University $\mathrm{Li}$ braries" is being published in its final form in this issue of CERL Neus for the information of ACRL members.

\section{STANDARDS}

\section{FOR UNIVERSITY LIBRARIES}

Prepared by a joint committee of the Association of Research Libraries and the Association of College and Research Libraries, a division of the American Library Association.

\section{Introduction}

These standards have been prepared to assist faculty, university administrators, librarians, accrediting agencies, and others in the evaluation and improvement of university library services and resources. These statements are intended to apply only to those institutions of higher education which have been characterized by the Carnegie Commission on Higher Education as "doctoral granting institutions." 1 All of these institutions emphasize graduate study, professional education, and research. Despite these basic similarities, university libraries are also characterized by a high degree of individuality, particularly with respect to policies, programs, responsibilities, and traditions. Hence, these standards are not intended to establish normative prescriptions for uniform application. Rather, they are meant to provide a general framework within which informed judgment can be applied to individual circumstances.

The fundamental assumption of these standards is that the library has a central and critical importance in a university. This importance has been recognized repeatedly by analysts of higher education. In his 1966 report to the American Council on Education, Allan M. Cartter, for example, stated:

The library is the heart of the university; no other single non-human factor is as closely related to the quality of graduate education. A few universities with poor library resources have achieved considerable strength in several departments, in some cases because laboratory facilities may be more important in a particular field than the library, and in other cases because the universities are located close to other great library collections such as the Library of Congress and the New York Public Library. But institutions that are strong in all areas invariably have major national research libraries."'2

As with all institutions, universities and their libraries have experienced considerable change over time. Further changes are taking place now, and others clearly lie ahead. Particularly noteworthy is the increasing sense of interdependence and commitment to coordination among universities generally. With regard to university libraries, the following developments are particularly important: the growth of interlibrary cooperation, especially resource sharing; the strengthening and expansion of service programs, such as bibliographic instruction; the increasing importance of recorded information in nonprint formats; the application of automated systems to library operations and the growth of machine-readable data bases; the closer interaction between librarians and faculty and the improved status of librarians within the university; increased stress on the effectiveness and efficiency of operations. A recognition of such trends and their importance is fundamental to these standards.

Recognizing the increasing interdependence of universities in developing and maintaining scholarly resources, these standards are intended to provide guidance in identifying that level of library self-sufficiency which is essential to the health and vigor of a university and its academic programs. The general assumption is that the primary obligation of a university library is to meet the instructional and research needs of the students and faculty at that university. However, no university library can acquire all of the recorded information that its clientele may find useful. An attempt is made, therefore, to recognize the mechanisms being developed to promote cooperative access to scholarly information, to identify the current limitations of interdependence, and to enumerate the factors which are essential in maintaining an environment in which instruction and research can flourish.

Care has been taken to limit the standards to succinct statements focusing on the elements judged to be most critical in determining the adequacy of a university library. Amplification of the principles identified in the standards is provided in the form of commentary. 


\section{Section A: Services}

\section{Standard A.I}

In order to support the instructional, research, and public service programs of the university, the services offered by a university library shall promote and facilitate effective use of recorded information in all formats by all of the library's clientele.

\section{Commentary on Standard A.1}

In developing and implementing its program of service, a university library should give priority to the needs of the students, faculty, and other academic staff of the university, who may be said to constitute the library's "primary clientele." While it may also have obligations or commitments to other clienteles or constituencies, the library should recognize that these are secondary.

A university library should provide the following services: reference and information services which are available at adequately identified and designated points during established service hours; specialized and in-depth assistance to individuals in the use of the library's resources; bibliographic instruction programs; services which will facilitate access to nonprint media and machine-readable data bases; and services which will facilitate access to recorded information in other library collections.

These services should be designed to meet effectively the whole range of different informational and bibliographical needs that arise in the various academic areas and in all other parts of the university.

While universities should place great emphasis on meeting the intensive library needs of graduate students and faculty, they should be careful to provide adequately for the needs of undergraduate students.

Finally, university libraries should recognize that, to one degree or another, they share a responsibility with all research libraries to support higher education in general and each other in particular through cooperative efforts.

\section{Standard A.2}

In order to ensure maximum access to its collections and their contents, a university library shall maintain records of its collections which are complete, consistent, and in conformity with national bibliographical standards and requirements.

\section{Commentary on Standard A.2}

The extent of bibliographical coverage that must be provided in a particular library will depend on many factors, such as whether or not the library has open or closed access stacks, the extent and nature of the library's specialized collections, the history and traditions of the library and of the university, and the nature of specific cooperative arrangements that the library may have entered into with other libraries and library consortia.

To ensure effective access to its collections as well as to increase its operational efficiency, a university library's bibliographic records should conform to recognized standards of cataloging and classification, and its bibliographic apparatus should be internally consistent. Its bibliographic records should be adjusted in conjunction with periodic inventories of the collections. Every multi-unit university library should have a union catalog of its cataloged holdings.

\section{Standard A.3}

Within the limits of the university's particular responsibilities and priorities, a university library shall provide maximum access to its collections for all of its clientele.

\section{Commentary on Standard A.3}

Various factors are involved in providing access to a library's collections, such as circulation policies and procedures, service hours, security arrangements, and actual operating efficiency. While practices vary significantly from library to library, certain principles should be followed in each library. Most items in the library collections should be readily available both for consultation in the library and for circulation to authorized clientele. Access to and circulation of rare, fragile, and high-demand materials should be appropriately controlled and restricted. To ensure maximum availability of the collections to those authorized to use them, terms of loan should be carefully set and should generally be similar for all user categories.

Adequate precautions should be taken to control loss of or damage to the library's collections. The prompt return in good condition of all circulated materials should be effectively enforced for all borrowers

Circulation procedures and stack maintenance operations in a university library should be effective and efficient. There should be a regular and continuing program of shelf reading. Library service hours should be responsive to high- and low-use periods, to the number of branch, departmental, and other special libraries in the system as well as to the availability of alternative study space.

\section{Section B: Collactions}

\section{Standard B.}

A university library's collections shall be of sufficient size and scope to support the university's total instructional needs and to facilitate the university's research programs.

\section{Commentary on Standard B.I}

A university library should provide all of the resources that are necessary for direct support of 
the university's full instructional programs at both the undergraduate and the graduate levels. If these resources are not readily available in the library, the instructional programs cannot be carried out successfully. These resources include required and assigned readings, reference and bibliographical materials, basic journals and serials, as well as any other library materials that undergraduate or graduate students are expected to be able to consult readily in their courses of study, or in the preparation of theses and dissertations.

Weak collections can hamper research. The accumulation and preservation of substantial collections and the implementation of comprehensive acquisition programs must be recognized as providing a resource whose presence within a university is essential to the conditions under which knowledge is effectively increased and transmitted. It is clear that no university library can be expected to possess in its collections all of the recorded information which faculty or doctoral students may need to consult as they pursue their research. Nevertheless, it is essential that collections be of such size, scope, and quality that they promote rather than restrict research. While every library should take care to develop collections whose areas of concentration reflect and support the academic priorities and strengths within the university, interlibrary arrangements, which have long been established for the mutual support of exceptional research needs, must continue to be relied upon to supplement even the most comprehensive research collections.

The continued rapid growth of scholarly literature and the costs of providing access to this literature for those in the university community have necessitated formal and informal arrangements among libraries to ensure maximum access to this literature. Common methods of sharing resources and improving access have been loans between libraries, provision of visiting privileges for scholars, agreements on the acquisitions of materials, and sharing of bibliographic information.

While interlibrary cooperation, as presently practiced, may not promise large cost savings in the immediate future, significant improved methods of supplementing local resources are in the active planning stages. University libraries must participate in the development of these new access mechanisms to ensure that local, regional, national, and international interests are effectively served.

Attempts have been made to identify precise quantitative measures of adequate collection size and growth rates for a university library. No such formula has yet been developed which can be generally applied. At present, such formulas as exist can only yield approximations which indicate a general level of need. If they are applied arbitrarily and mechanically, they can distort the realities of a given situation. Nevertheless, quan- titative measures are increasingly important in guiding the qualitative judgment that must ultimately be applied to university libraries and their collections. One technique is the use of regression analysis to facilitate the comparison of similar libraries to one another, ${ }^{3}$ another of some general applicability is the "index of quality" developed by the American Council on Education for relating library collection size to graduate program quality. ${ }^{4}$

\section{Standard B.2}

A university library's collections shall be deceloped systematically and consistently within the terms of explicit and detailed policies.

\section{Commentary on Standard B.2}

Given the great breadth of university library collections and the wide variations in depth of collections among subjects held, it is essential that there be a collections development policy to guide the selection and acquisition of materials.

By establishing such a policy, librarians seek to ensure that the library's collections are planned and developed in relation to the university's academic, research, and service goals and priorities and within the limits of resources available.

Working in close consultation with faculty and administration, librarians, particularly subject specialists, should assume the responsibility for drafting and implementing this policy.

Recognizing the inherent difficulties in collection development, it is imperative that the library have full and continuous access to information about all developments, actual and planned, in the academic, research, and service programs of the university and its components which affect the library.

Once codified, the library's collection development policy should be made known to and endorsed by the university faculty and administration. To ensure that this policy reflects changes within the university, the policy should be regularly and carefully reviewed.

\section{Standard B.3}

A university library's collections shall contain all of the caried forms of recorded information.

\section{Commentary on Standard B.3}

The university library has traditionally been recognized as the repository within the university for the printed information needed to support the university's instructional and research programs. As recorded information becomes increasingly available in a variety of nonprint formats, such as films, sound recordings, and video tapes, it is appropriate that this material, except where needed exclusively for classroom use, also be acquired, organized, and made available through the university library. ${ }^{5}$ 


\section{Section C: Personnel}

\section{Standard C.1}

A university library shall have a sufficient number and variety of personnel to develop, organize, and maintain such collections and to provide such reference and information services as will meet the university's needs.

\section{Commentary on Standard C.1}

The size of a university library's staff is determined by many factors, including the number of physically separate library units, the number of service points requiring staff, the number of service hours provided, the number and special characteristics of items processed annually, the nature and quality of the processing to which they are subjected, the size of the collections, and the rate of circulation of the collections. Interinstitutional cooperative arrangements may also affect staff size. As such factors vary widely from one institution to another, no single model or formula can be provided for developing an optimum staff size.

A university library should have on its staff a variety of personnel: professional, clerical, and student-assistant staff. The librarians should perform the core academic and professional functions of the library: collection development, reference and information services, and substantive activities related to the bibliographic control of materials. All categories of personnel should have appropriate education and experience, including, when necessary, graduate or professional degrees in their particular specialties. The recognized terminal degree for librarians is the master's degree from an American Library Association accredited library school program, although additional graduate degrees may sometimes be desirable.

The deployment of personnel within a specific university library is related to the range of operations and services provided by that library and to its total workload requirements.

\section{Standard C. 2}

Personnel practices within a unicersity library shall be based on sound, contemporary administrative practice and shall be consistent with personnel practices within the university as well as the goals and purposes of the library.

\section{Commentary on Standard C.2}

The terms and conditions of employment of the several categories of staff in a university library should be consonant with the established terms and conditions of employment of staff in related categories elsewhere within the university. Terms and conditions of employment for librarians, for example, should parallel those of the rest of the university's academic staff, just as terms and con- ditions of employment for the library's clerical and student staff should parallel those of similar employees within the university as a whole.

A comprehensive university library personnel management program should address recruitment, appointment, promotion, tenure, dismissal, appeal, definition of position responsibilities, classification and pay plans, orientation and training programs, review of employee performance, staff development, and counseling.

More specific guidance on these matters is provided in the following documents: "Statement on Faculty Status of College and University Librarians" 6 and "Library Education and Personnel Utilization."7

\section{SECTION D: FaCiLITIES}

\section{Standard D.1}

A university library shall have facilities which meet the present and anticipated future requirements of the university and its programs.

\section{Commentary on Standard D.1}

A university library's buildings should be of sufficient size and quality to house the collections and to provide sufficient space for their use by students, faculty, and other clientele. There should also be adequate space for the library operations necessary for the provision of its services. Adequacy of facilities cannot be determined simply on the basis of present requirements. The size and composition of the university's enrollment, the nature of its instructional and research programs, the form and publication rate of library materials strongly influence library requirements, and it is necessary that these requirements be subject to continuous evaluation and planning.

A university library should be attractive, inviting, and carefully designed to promote operational efficiency and effectiveness of use. Specific factors relevant here include general environmental features that affect clientele, staff, and collections (light, ventilation, temperature and humidity control, vertical and horizontal transportation, safety features, etc.), layout of the stacks, number and variety of reader stations, relationship between stacks and reader stations, relationship among service points, effective flow of materials, and adequacy of space for staff and operations.

The fundamental consideration in designing a library building should be its function. Since the nature of collections, services, operations, and the needs of a library's clientele can change significantly over time, present and future flexibility is an important element in library design. Although the architectural style and traditions of a university may dictate certain design features for a library building, such factors should not be allowed to compromise basic functional considerations. $^{8}$ 


\section{Standard D.2}

Libraries shall be so located that the university community will have convenient access to them.

\section{Commentary on Standard D.2}

The requirements of interdisciplinary studies and research, recognition of the needs of undergraduate students, the urgency of achieving operating economies - these and other factors have revived interest in centralizing physically dispersed library units in order to improve access to resources and avoid costly duplication in the development and maintenance of collections. There are circumstances, however, such as campus geography, intensity of use, and size of collections which may continue to justify the maintenance of multiple library units. Remote storage facilities may also be established in attempting to deal with space inadequacies although this usually inhibits convenience of access. Where the pattern of decentralization persists in any form, it is important that libraries be located so as to minimize inconvenience to all library users. ${ }^{9}$

\section{Section E: Administration AND GoNERnANCE}

\section{Standard E.1}

The place of the university library within the administrative and governance structure of the university shall be clearly identified, and the responsibilities and authority of the library administration and its chief administrative officer shall be defined.

\section{Commentary on Standard E.1}

If there is ambiguity within the university community as to the particular place occupied by the library within the administrative and governance structure of the university, and if the authority and responsibilities of the library's chief administrative officer are not clearly identified, misunderstanding, conflict, and confusion can sometimes result to the detriment of both the university and its library. Because it is closely related to instruction and research, the university library should be formally recognized as one of the major academic units within the university, and its chief administrative officer should participate regularly and directly in university-wide academic planning and decision making. For similar reasons, this person should report directly to the chief academic officer of the university.

The long-recognized need in institutions of higher education to involve faculty in library matters has led to the institutionalization of the advisory library committee. Because of the fundamental importance of the library to instruction and research and the consequent need for close, continuing interaction between the faculty and the library, the existence of the library committee is valuable. The committee should be advisory, and its responsibilities should be clearly delineated.

\section{Standard E.2}

The university library's own administrative and governance structure shall be clearly specified and shall be consonant with the governance structure of the university as well as with the particular needs and requirements of the library.

\section{Commentary on Standard E.2}

In order to facilitate effective organizational activity and decision making, it is essential that the administrative and governance structure of the university library itself be clearly specified. This will involve identifying the roles and responsibilities of all categories of library personnel in the governance of the library. It is essential that library governance reflect the principles and practice followed elsewhere within the university, although they should be modified as necessary to embody those conditions and issues peculiar to an academic library.

\section{Standard E.3}

There shall be a close administrative relationship among all libraries within the university to the end that library users may make full and effective use of library resources and services.

\section{Commentary on Standard E.3}

No single pattern of library administration will serve all universities equally well, but whatever pattern an institution chooses should have as its principal purpose the equitable distribution of library resources and services. The needs of scholars differ from discipline to discipline and often the needs of students differ from those of faculty. These competing interests cannot always be reconciled, but one important task of library administration is to achieve as much balance as possible in the provision of services to all groups.

However administrative relationships among library units within a university are determined, it is essential that adequate coordinating mechanisms be established and enforced to ensure that service policies are in reasonable harmony, that costs related to duplication are controlled, and that access to all library collections is maximized.

\section{Standard E.4}

A university library's major policies and procedures shall be clearly defined and regularly reviewed.

\section{Commentary on Standard E.4}

In order to ensure that it is effective internally and understood externally, a university library should clearly define its major policies and procedures and record them in written form. The written statements of policy should be readily 
available to all members of the library staff, and policies which have external relevance (such as the library's collection development policy or circulation policy) should be accessible to the library's clientele and to others who may need or desire to consult them. These policies, as well as the practices that implement them, should be regularly reviewed to ensure that they continue to be appropriate.

\section{Section F: Finance}

\section{Standard F.1}

Budgetary support for the university library shall be sufficient to enable it to fulfill its obliga tions and responsibilities as identified in the pre ceding standards.

\section{Commentary on Standard F.1}

The total budgetary needs of a university library can be determined only in relation to its responsibilities. Many attempts have been made to develop formulas or other "objective" measures for determining the budgetary requirements of a university library. These measures range from matching funding with student enrollment to defining a minimum percentage of the total university $G$ and $\mathbf{E}$ budget which should be devoted to the library. Such "objective" approaches to budget determination do not always take cog nizance of the range and complexity of demands which any university library must meet, as well as the significantly different library needs of different universities.

These conditions also make it impossible to identify a viable model that can be applied to all university libraries for allocating their budgets by major category (salaries and wages, acquisitions, binding, miscellaneous supplies, and other expense). Allocation ultimately depends on local requirements and priorities. For example, if a university library is expected to operate a substantial number of discrete units with parallel and duplicative activities, its expenditures for salaries and wages will be higher than if this were not the case.

Under any circumstances, it is essential that a university library be provided with sufficient funding to enable it to develop appropriate collections, provide appropriate services, carry out necessary operations, and satisfy identified expectations and requirements. If funding is less than is necessary to fulfill these obligations, the library will be unable to meet university needs.

A university library should be expected to operate on a sound financial basis. To do this, the library and its administration must be able to identify and support its fiscal request effectively and to report adequately on expenditure of funds.

\section{Standard F.2}

The university library budget shall be a distinct part of the university's budget, and it shall be developed and managed by the chief administrative officer of the university library.

\section{Commentary on Standard F.2}

The authority to prepare, submit, defend, and administer the university library budget should be delegated clearly and explicitly to the chief administrative officer of the university library. He or she should have full responsibility for managing this budget as well as the authority necessary to maximize the use of the library's total resources. He or she should have the same degree of latitude and responsibility that is exercised by other major administrative officers within the university. The library should be responsible for preparing adequate and regular reports on expenditures throughout the year. These reports should conform to the university's requirements and, where necessary, to its standardized procedures and practices.

Because of the importance of the library within the university and the need that it respond effectively to changing demands, priorities, and academic programs, it is essential that the library budget be developed in relationship to and with full cognizance of the total university budgetplanning process, and that the library's chief administrative officer be directly and significantly involved in this process.

\section{REFERENCES}

1. Carnegie Commission on Higher Education, $\boldsymbol{A}$ Classification of Institutions of Higher Education (Berkeley, Calif.: The Commission, 1973), p.1-2, 9-22. This publication identifies 173 "doctoral granting institutions."

2. Allan M. Cartter, An Assessment of Quality in Graduate Education (Washington, D.C.: American Council on Education, 1966), p.114.

3. William J. Baumol and Matityahu Marcus, Economics of Academic Libraries (Washington, D.C.: American Council on Education, 1973).

4. Cartter, An Assessment of Quality in Graduate Education, p.114.

5. The best recent discussion of the importance of nonprint media for higher education is Carnegie Commission on Higher Education, The Fourth Revolution: Instructional Technology in Higher Education (New York: McGrawHill, 1972).

6. In Faculty Status for Academic Librarians: A History and Policy Statement (Chicago: American Library Assn., 1975), p.35-38.

7. "Library Education and Personnel Utilization" (Chicago: American Library Assn., 1976).

8. Considerable valuable information is available in several publications, the best of which remains Keyes D. Metcalf, Planning Academic and Research Library Buildings (New York: McGraw-Hill, 1965).

9. This issue has been the subject of considerable 
analysis. See, particularly, Ralph E. Ellsworth, The Economics of Book Storage in Academic Libraries (Metuchen, N.J.: The Association of Research Libraries and the Scarecrow Press, 1969). Also useful is Jeffrey A. Raffel and Robert Shishko, Systematic Analysis of University Libraries (Cambridge, Mass.: MIT Press, 1969).

\section{APPENDIX}

\section{Quantitative ANaLyTiCal TeChniques FOR UNIVERSITY LIBRARIES}

The university libraries ${ }^{1}$ to which quantitative measures might be applied are so complex, so diverse in the programs they support, and so different from each other that it is extremely difficult, if not impossible, to devise a common statistical measure which could be applied to all of them. This problem is further complicated by the character and inadequacy of the currently available data. Herman Fussler, for example, observes that "libraries, like universities, tend to have very inadequate analytical data on their own operations and performance. Such data, especially as they relate to costs and system responses to user needs, are critically important in any effort to improve a library's efficiency and responsiveness. "2 Fritz Machlup, in the course of his recent efforts to measure the holdings and acquisitions of libraries on a broad scale, has complained about the lack of adequate data. ${ }^{3}$ Other observers have challenged the utility of present library data collection." They focus on perceived failures to measure performance or effectiveness. Nevertheless, academic institutions do compete for faculty and students, and one of the elements in this competition is the adequacy of library services and collections. Comparative judgments about academic libraries are made, and these comparisons can be aided by quantitative measures.

Unfortunately, much of the data which are needed to actually make interinstitutional comparisons is not easily available, although some useful data can be obtained from ARL statistics. The LIBGIS and HEGIS surveys also supply data, but these are usually too old for current needs or in a form which is difficult to use. Consequently, the analyst is compelled to rely on what is available: ARL statistics, authorities who have written on the subject, and such limited surveys as he or she can make. All of these methods have varying degrees of utility, but with the possible exception of the ARL data, none provide the raw data on which empirically derived measures can be based. Certain "common" practices can be discerned, and the advice of authorities can be weighed, but these, however valuable, do not constitute quantitative measures in an empirically derivable, logically justifiable sense. To have reliable quantitative measures, the categories to be measured must be defined, and a mechanism for gathering the necessary data must be developed.

In the absence of either of these necessary conditions, it is difficult to do more than perform what analyses can be performed on ARL data. Briefly, these fall into three categories: (a) insights obtained by simple inspection of the data; (b) the construction of ratios which reduce the quantity of data to be comprehended and facilitate comparison; and (c) regression analysis which performs roughly the same function from the analyst's point of view as the construction of ratios but also requires an effort on the part of the analyst to group like institutions together and gives the analyst some indication of how well this has been accomplished (coefficient of determination).

Simple inspection of ARL data, aided by rankings, ranges, averages, and medians, does provide useful insights for the experienced library manager who can mentally discount obvious discrepancies and differences between institutions and can restrict comparisons to a homogeneous group. However, to read, for example, that in 1976-77 the number of volumes in ARL libraries ranged between Harvard's 9,547,576 and McMaster's 906,741 , that the average library held $2,127,047$, and the median was $1,653,000$ may give the reader a sense of perspective, which is valuable, but it is of limited use in drawing comparisons between rather different institutions.

A reduction of data can be achieved by the use of ratios or percentages, as is shown in the example of ratio analysis below. Some of those which can be generated from existing data include:

1. The ratio of professional to nonprofessional staff

2. Expenditure for library materials as a percent of total library operating expenditure

3. Ratio of salary expenditures to library material expenditures

This kind of data reduction aids analysis by mak ing the data more comprehensible. For example, among ARL libraries in $1976-77$, the ratio of professional to nonprofessional staff ranged from 1.08 to 0.24 ; the average was 0.51 and the median 0.49 . The overwhelming majority of libraries tended toward a pattern of one professional to two nonprofessionals. Among ARL libraries in 1976-77, expenditures for library materials as a percent of total library expenditures ranged from 19.14 percent for Toronto to 50.61 percent for Houston. The average was 31.46 percent and the median 30.09 percent. The vast majority of ARL libraries tended to spend 30 percent of their budgets on acquisitions. The obverse of materials expenditure for libraries is salary expenditure. Expressed as a ratio of salary to materials it ranged from 3.6 in the case of Toronto, to 0.8 in the case of Houston, with the median 1.9 and the average 1.93

From ratios such as these, a deeper insight into 
library operations can be obtained, but it would be rash to conclude that all libraries should spend 30 percent of their budgets for books and 60 percent for salaries or that the ratio of professional to nonprofessional should always be 1:2. Local conditions dictate differing policies. A library with many branches may require a higher ratio of professionals to nonprofessionals. Conversely, differing operating conditions, different types of staffing may dictate different ratios. An example of a more extended kind of ratio analysis is that of Allan Cartter's Library Resources Index, which is described in a following section. Yet, even this kind of ratio should be viewed cautiously. At best, ratio analysis can serve only as a background against which local conditions may be evaluated.

Regression analysis also provides a form of data reduction, but it compels the analyst to attempt to group like institutions together. Baumol and Marcus provide a guide to its use in library data analysis. ${ }^{5}$ The concluding section of this appendix gives an example of its application. But the same caveats about drawing inferences that apply to ratio analysis apply to regression analysis.

In addition to these, there is a growing literature on performance evaluation of libraries which is expressed in various ways. F. W. Lancaster summarizes some of the possible approaches:

"1. The ability of the library to deliver a particular item when it is needed.

"2. The ability of the catalog and the shelf arrangement to disclose the holdings of particular items or of materials on particular subjects.

" 3 . The ability of reference staff to answer questions completely and accurately.
"4. The speed with which a particular item can be located when needed.

"5. The speed with which a reference inquiry can be answered or a literature search conducted and the results presented to the library user.

"6. The amount of effort that the user must himself expend in exploiting the services of the library (including factors of physical accessibility of the library and its collections, the size and quality of the library staff, and the way in which the collections are cataloged, indexed, shelved and signposted." 6

Performance measures are, however, still in the early stages of their development. They may eventually prove to be extremely important to libraries, but they are likely to be most useful in making intrainstitutional rather than interinstitutional decisions. In sum, there are no simple solutions, no ready panaceas, no easily available substitutes for intelligent analysis of available data.

\section{Example of Ratio Analysis}

Table 1 below demonstrates the application of ratio analysis to library materials expenditures as a percentage of total library operating expenditures. It is based on the latest (1976-77) ARL data. For the sake of brevity and because this is simply used as an example, only twenty of the total applicable ninety-three institutions have been included.

\section{The Library Resources Index}

The Library Resources Index is a specialized index devised by Allan M. Cartter and published

TABLE 1

Library Materials Expenditlies as a Percentage of Total Library Operating Expenditures (Valle) FOR TWENTY UNIVERSITY LIBRARIES, 1976-77

\begin{tabular}{cclc}
\hline $\begin{array}{c}\text { Hank Order } \\
\text { Number }\end{array}$ & $\begin{array}{c}\text { Institution } \\
\text { Number }\end{array}$ & Institution Name & Value \\
\hline 1 & 31 & Houston & 50.61 \\
2 & 3 & Arizona & 44.63 \\
3 & 82 & Texas A M & 44.05 \\
4 & 87 & VPI \& & 42.84 \\
5 & 81 & Texas & 42.69 \\
6 & 28 & Georgia & 42.21 \\
7 & 35 & Iowa & 42.15 \\
8 & 71 & South Carolina & 42.08 \\
9 & 68 & Rice & 41.67 \\
10 & 42 & Louisiana State & 40.19 \\
11 & 20 & Connecticut & 40.04 \\
12 & 60 & Oklahoma State & 39.51 \\
13 & 53 & Nebraska & 39.30 \\
14 & 80 & Tennessee & 39.22 \\
15 & 52 & Missouri & 38.93 \\
16 & 4 & Arizona State & 38.62 \\
17 & 22 & Dartmouth & 38.30 \\
18 & 24 & Emory & 38.23 \\
19 & 1 & Alabama & 38.08 \\
20 & 57 & Notre Dame & 37.87 \\
\hline
\end{tabular}


TABLE 2

The Librahy Resources IndeX APPLIED

TO TWENTY ARL LiBRARIES, 1976-77

\begin{tabular}{|c|c|c|c|c|c|}
\hline $\begin{array}{c}\text { Rank Order } \\
\text { Overall } \\
\text { Index }\end{array}$ & Institution Name & $\begin{array}{l}\text { Total } \\
\text { Volume } \\
\text { Index }\end{array}$ & $\begin{array}{l}\text { Volumes } \\
\text { Added } \\
\text { Index }\end{array}$ & $\begin{array}{l}\text { Serials } \\
\text { Index }\end{array}$ & $\begin{array}{c}\text { Overall } \\
\text { Library } \\
\text { Resources } \\
\text { Index }\end{array}$ \\
\hline 1 & Harvard & 4.49 & 2.25 & 3.89 & 3.54 \\
\hline 2 & Illinois & 2.74 & 1.95 & 3.43 & 2.71 \\
\hline 3 & Yale & 3.24 & 2.40 & 2.44 & 2.69 \\
\hline 4 & Calif., Berkeley & 2.31 & 1.75 & 3.90 & 2.65 \\
\hline 5 & Texas & 1.91 & 2.87 & 2.41 & 2.39 \\
\hline 6 & Indiana & 2.07 & 2.39 & 1.71 & 2.05 \\
\hline 7 & Columbia & 2.22 & 1.57 & 2.31 & 2.03 \\
\hline 8 & Michigan & 2.31 & 1.81 & 1.92 & 2.02 \\
\hline 9 & Stanford & 2.05 & 1.67 & 2.13 & 1.95 \\
\hline 10 & Toronto & 1.87 & 2.15 & 1.66 & 1.90 \\
\hline 11 & Calif., Los Angeles & 1.84 & 1.44 & 2.26 & 1.84 \\
\hline 12 & Washington & 1.52 & 2. 16 & 1.64 & 1.77 \\
\hline 13 & Cornell & 1.87 & 1.33 & 2.08 & 1.76 \\
\hline 14 & Chicago & 1.83 & 1.60 & 1.76 & 1.73 \\
\hline 15 & Wisconsin & 1.52 & 1.30 & 1.92 & 1.58 \\
\hline 16 & Ohio State & 1.53 & 1.50 & 1.15 & 1.39 \\
\hline 17 & Minnesota & 1.58 & 0.93 & 1.48 & 1.33 \\
\hline 18 & Duke & 1.35 & 1.28 & 1.33 & 1.32 \\
\hline 19 & Princeton & 1.37 & 1.18 & 1.25 & 1.27 \\
\hline 20 & Pennsylvania & 1.31 & 1.08 & 1.10 & 1.16 \\
\hline
\end{tabular}

in his An Assessment of Quality in Graduate Education. ${ }^{7}$ It is an average of three indexes and is computed in the following way. First, the pool of institutions to be compared is determined. (In the example, shown as table 2, this pool is all ARL libraries and the data are for 1976-77). Second, three variables are isolated: (a) total volumes; (b) volumes added; and (c) periodicals received. A separate index is formed for each variable by finding the average for each variable and dividing the average value into the value for each institution.

For example, assume that the average number of periodicals held in ARL libraries is 15,000 , and three institutions have totals respectively of $60,000,15,000$, and 7,500 . Dividing the average, 15,000 , into each of these figures yields index values of 4,1 , and .5. Similarly, values are found for each institution for the other two variables: volumes added and total volumes. Then the three index values for each institution are summed, divided by three, and sorted into descending order. For example, refer to institution number 8 in table 2. It is Michigan. It has index values of $2.31,1.81$, and 1.92 . The sum of these is 6.04 . Dividing this by 3 yields 2.01 , the overall library resources index.

Mr. Cartter's index was based on 1963-64 data. His general conclusion at that time was: "Those libraries which fall below .5 are probably too weak to support quality graduate programs in a wide range of fields, although they may be adequate for an institution that specializes in technology or in advanced work in a very limited number of areas. "8

Table 2 demonstrates an application of the $\mathrm{Li}$ - brary Resources Index to twenty ARL libraries, using 1976-77 ARL data.

Regression Analysis Tables Using ARL Data, $1975-76$

In analyzing data from ARL libraries, the strongest statistical relationships are found to exist when these libraries are categorized in some way. Therefore, by way of example, ARL libraries may be grouped in four different ways:

1. All ARL academic libraries.

2. All private ARL academic libraries in the U.S.

3. All public ARL academic libraries in the U.S.

4. All Canadian ARL academic libraries.

Further, for each group additional tables may be developed that predict the values of certain different (dependent) variables based upon the value of other (independent) variables. Six variables, for example, which can be examined are:

1. Professional staff

2. Total staff

3. Gross volumes added

4. Expenditures for library materials

5. Total library expenditures

6. Current periodicals held

For each library in each of the four groups noted above, the following predictions then can be made:

1. Number of professional staff based on number of volumes held

2. Number of total staff based on number of volumes held

3. Number of gross volumes added based on volumes held 
TABLE 3

EXAMPLE of Regression ANalysis A PPLIED to Size of Professional Staff (Y)

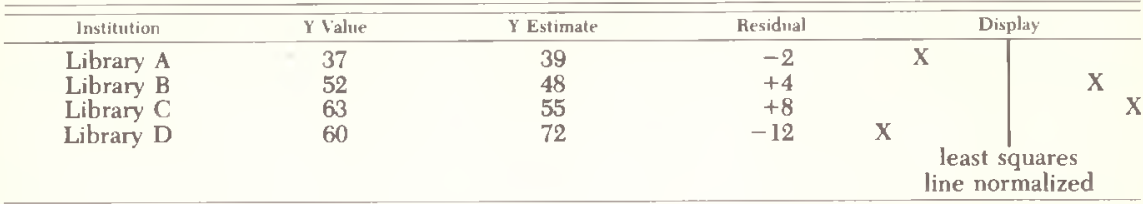

4. Expenditures for library materials based on gross volumes added and volumes held

5. Total expenditures based on volumes held, gross volumes added, and total staff

6. Number of current serials based on number of volumes held

Thus, for each table there can be plotted a display of variables, together with observations for each institution, and which include for each dependent variable its actual value, its estimated value, and the residual, which is the difference between the actual and the estimated value. For example, assume we have the display shown above as table 3 , which predicts the number of professional staff a library is expected to have based upon the number of volumes held.

The first column identifies each institution; the second shows the actual value for each variable; the third shows the expected value based on the regression equation computation which has been done; the fourth is the difference between columns two and three; and the fifth is a plot of the data.

Looking at Library $A$, we see that it has thirty-seven professional staff, but based on the other libraries in its comparison class, it would be expected to have thirty-nine. The actual value is two fewer than expected, so its position on the graph is plotted to the left of the least squares line. (See any standard textbook on statistics for detailed explanation of this technique.) Libraries $B$ and $C$ have more professionals than would be expected, so they are plotted to the right of the line. Consequently, by inspection, the library manager can note any obvious anomalies between his or her institution and others.

\section{ReferenCES for APPENDIX}

1. Doctoral granting institutions in Carnegie Commission on Higher Education. A Classification of Institutions of Higher Education (Berkeley, Calif.: The Commission, 1973). p. 1-2, 9-22.

2. Herman H. Fussler, Research Libraries and Technology, A Report to the Sloan Foundation (Chicago: Univ. of Chicago Press, 1973), p.61.

3. Fritz Machlup, "Our Libraries: Can We Measure Their Holdings and Acquisitions," AACP Bulletin 62:303-7 (Oct. 1976).

4. See, for example, Morris Hamburg and others, Library Planning and Decision Making Systems (Cambridge, Mass.: MIT Press, 1974).

5. William J. Baumol and Matityahu Marcus, Economics of Academic Libraries (Washington, D.C.: American Council on Education, 1973).

6. F. W. Lancaster, The Measurement and Evaluation of Library Sercices (Washington, D.C.: Information Resources, 1977), p.323.

7. Allan M. Cartter, An Assessment of Quality in Graduate Education (Washington, D.C. American Council on Education, 1966).

8. lbid., p. 114 .

Editor's Note: Members may order single copies by sending a self-addressed label to the ACRL office. Nonmembers should include $\$ 1.00$ with their order 